\title{
A construção de conhecimento nas comunidades virtuais do ciberespaço
}

\author{
Inácio Szabó ${ }^{1}$ \\ UFBA \\ inacio@reconcavotecnologia.org.br \\ Rubens Ribeiro Gonçalves da Silva ${ }^{2}$ \\ UFBA \\ rubensri@ufba.br
}

\begin{abstract}
Resumo: Aborda as transformações que a internet e o ciberespaço vêm promovendo nas últimas décadas, com relação ao conhecimento e à informação. Propõe reflexão sobre a construção do conhecimento a partir das relações humanas no ciberespaço. Investiga uma nova forma de organização social, as comunidades virtuais de conhecimento, apresentando a tensão dialética entre a Rede e o Ser, neste momento histórico da "Sociedade em Rede". Conclui indicando o importante papel das comunidades virtuais de conhecimento na transição da Sociedade em Rede para a Sociedade do Conhecimento, e apontando a relevância da investigação acerca do desenvolvimento e da disseminação das potencialidades desta prática de comunicação.
\end{abstract}

Palavras-chave: Ciberespaço; Comunidades Virtuais de Conhecimento; Sociedade do Conhecimento

Resúmen: Este artículo presenta las transformaciones que el internet y el ciberespacio están produciendo en lãs últimas décadas, con respecto al conocimiento y la información. Se propone una reflexión acerca de la construcción del conocimiento desde una perspectiva de las relaciones humanas en el ciberespacio. Además, trata de investigar una nueva forma de organización social, las comunidades virtuales de conocimiento, y presentar la tensión dialéctica entre la Red y el Ser, en este momento histórico de la "Sociedad en Red". La conclusión indica el importante rol de las comunidades virtuales del conocimiento en la transición de la Sociedad en Red para la Sociedad del Conocimiento, y apunta para la relevancia de la investigación acerca del desarrollo y la diseminación de potencialidades de esta práctica de comunicación."

1 Mestrando em Ciência da Informação (POSICI/UFBA); bacharel em Engenharia de Computação (UNICAMP); Instituto de Ciência da Informação da Universidade Federal da Bahia (ICI/UFBA).

2 Dr. em Ciência da Informação (UFRJ-ECO/IBICT-DEP, 2002); professor adjunto do Departamento de Fundamentos e Processos Informacionais (DFPI/ICI/UFBA) e do Programa de Pós-Graduação em Ciência da Informação (POSICI/UFBA); Instituto de Ciência da Informação da Universidade Federal da Bahia (ICI/UFBA). 
Palabras-llave: Ciberespacio; Comunidades Virtuales de Conocimiento; Sociedad del Conocimiento

\begin{abstract}
Abrégé: Il aborde les transformations que l'Internet et le Cyberspace favorise les dernières décennies, en ce qui concerne la connaissance et l'information. Il suggère la réflexion sur la construction de la connaissance a partir des relations d'êtres humains dans Cyberspace. Il examine une nouvelle forme d'organisation sociale, les communautés virtuelles de la connaissance, en présentant la tension dialetique entre le Réseau et l'Être, à ce moment historique de la «Network Society». Il conclut em indicant le rôle important des communautés virtuelles de la connaissance dans la transition de la Network Society a la Société de la Connaissance, et aussi en indicant la relevance de la recherche sur le développement et la diffusion des potentialités de cette pratique de communication.
\end{abstract}

Mot-clé: Cyberspace; Communautés Virtuelles de la Connaissance; Société de la Connaissance

Abstract: It approaches the transformations that Internet and cyberspace promotes last few decades, with regard to knowledge and information. It suggests a reflection on the construction of knowledge get from the human beings relations in cyberspace. It investigates a new form of social organization, the virtual communities of knowledge, presenting the dialectic tension between the Net and the Being, at this historical moment of "Network Society". It concludes indicating the important role of virtual communities of knowledge in the transition of Network Society for Knowledge Society, and pointing the relevance of the inquiry concerning the development and the dissemination of potentialities of this practice of communication.

Key-words: Cyberspace; Virtual Communities of Knowledge; Knowledge Society.

\title{
1 Introdução
}

Este artigo é resultante da pesquisa para a dissertação de mestrado que vem sendo desenvolvida no Programa de Pós-Graduação em Ciência da Informação do Instituto de Ciência da Informação da Universidade Federal da Bahia (POSICI/ICI/UFBA). Na pesquisa procuramos entender o processo de informação e a inteligência coletiva nas comunidades virtuais de conhecimento do ciberespaço, e como se desenvolvem e se disseminam estas comunidades. 
Propomos a reflexão acerca da construção do conhecimento e da aplicação das teorias sociais do conhecimento para o estudo das comunidades virtuais estabelecidas através das relações humanas no ciberespaço. Serão preliminarmente apresentados os conceitos de conhecimento e informação nos quais se fundamenta a proposta, bem como as concepções de Castells (1999), Lévy (1999; 2001) e Rheingold (1996) sobre o ciberespaço e as comunidades virtuais. A partir destes conceitos será proposto o conceito de comunidades virtuais de conhecimento.

A Ciência da Informação (CI) tem como um de seus propósitos a investigação da comunicação do conhecimento em um contexto social, com particular interesse no máximo aproveitamento das possibilidades oferecidas pela tecnologia (SARACEVIC, 1992). Entende-se, portanto, que a reflexão sobre o conhecimento no ciberespaço torna-se um tema central da CI, considerando a crescente importância para a humanidade do uso deste meio para a prática de comunicação. É de particular interesse a abordagem do conhecimento associado à possibilidade de transformação da sociedade por meio da ação humana.

\section{A dialética entre a rede e o ser}

Este momento histórico em que se caracteriza a Sociedade em Rede é também um momento paradoxal da história da humanidade. Ao mesmo tempo em que estamos cada vez mais interconectados através das redes, testemunha-se a escalada de conflitos étnicos e religiosos ao redor do planeta. Por outro lado, o exercício da cidadania se dá, principalmente, através do consumo privado, caracterizando o aprofundamento do abismo social em todo o mundo.

Castells (1999) considera que no mundo globalizado, no qual ocorrem fluxos globais de riquezas, poder e imagens, a significação social se dá a partir da busca da identidade. $\mathrm{O}$ autor entende a identidade como "o processo pelo qual um ator social se reconhece e constrói significado, principalmente com base em determinado atributo cultural ou conjunto de atributos, a ponto de excluir uma referência mais ampla a outras estruturas sociais." (CASTELLS, op.cit., p.57) . 
Por um outro enfoque, complementar, Canclini (1995, p.226) afirma que "a revitalização dos nacionalismos, regionalismos e etnicismos, desde a última curva do século $\mathrm{XX}$, pretende reduzir o trabalho histórico da construção e readaptação incessante das identidades à simples exaltação de tradições locais". E em casos extremos, observa-se que o fundamentalismo belicista com que muitos movimentos atuam anula as possibilidades de negociação.

Segundo Lévy (2001), o adensamento das comunicações e o retraimento do espaço comum tornam mais visíveis que nunca as predominâncias e as disparidades. Lévy percebe uma tensão dialética entre o movimento dos centros em direção ao futuro, tornando-se cada vez mais conectados, e trazendo para si as periferias, ao mesmo tempo em que acentuam sua distância em relação ao resto do mundo, que permanece na marginalidade, no buraco negro econômico, social e intelectual.

Parece haver concordância, entretanto, de que as redes eletrônicas e a globalização nos fazem cada vez mais próximos e mais conscientes do próximo. Conforme lembrado por Gaspari (2004), se hoje ficamos sabendo quase que imediatamente sobre um tsunami na Ásia, e nos mobilizamos através das redes para fornecer o apoio necessário às vítimas, há um século uma catástrofe como a erupção do vulcão Krakatoa só era noticiada após meses, e a preocupação dos representantes das metrópoles era muito mais com a pastagem para o gado de corte do que com as vítimas. A Unesco (2005) destacou a importância da Internet para a mobilização da campanha internacional em apoio às nações atingidas pelo tsunami em 2004.

Castells (op. cit.) cita a questão proposta por Calderon e Laserna a respeito dos paradoxos de "um mundo caracterizado por globalização e fragmentação simultâneas":

Como combinar novas tecnologias e memória coletiva, ciência universal e culturas comunitárias, paixão e razão? E por que observamos a tendência oposta em todo o mundo, ou seja, a distância crescente entre globalização e identidade, entre a Rede e o Ser? (CALDERON e LASERNA, 1994, apud CASTELLS, 1999, p. 58)

Nesta questão proposta por Calderon e Laserna, entendemos o Ser como a individualidade de um ator social, fundamentada em seu processo de identidade. Nosso objetivo é refletir sobre essa no campo da CI, concentrando a investigação particularmente 
sobre o ciberespaço: as relações humanas que se estabelecem nas redes do ciberespaço excluem as identidades dos indivíduos? Essas relações possibilitam o conhecimento e a ampliação da consciência dos envolvidos?

\section{Conhecimento, informação e conteúdo informacional}

Esta seção apresenta os conceitos de conhecimento e informação que fundamentam nossa proposta. O objetivo da apresentação destes conceitos não é o de imposição dogmática, mas sim uma oportunidade para reflexão, uma vez que estes conceitos se mostram consistentes para pensarmos o conhecimento no campo da CI.

Schaff (1986) apresenta três modelos do processo de conhecimento :

1. Modelo Mecanicista:

O conhecimento neste modelo é baseado na construção mecanicista da Teoria do Reflexo. ${ }^{3} \mathrm{O}$ objeto atua sobre o aparelho perceptivo do sujeito, que é um agente passivo, contemplativo, e receptivo. O produto deste processo o conhecimento - é a cópia do objeto, cuja gênese se dá na relação mecânica do objeto sobre o sujeito, por isso o modelo é chamado de mecanicista.

2. Modelo Idealista:

No modelo idealista, a predominância na relação sujeito-objeto se volta para o sujeito que conhece, que percebe o objeto do conhecimento como sua produção. Este modelo concretizou-se em diversas filosofias subjetivistasidealistas. ${ }^{4}$

3. Modelo Ativista:

Já no modelo ativista, ocorre a preponderância da interação sujeito-objeto na construção do conhecimento. Esta interação produz-se no enquadramento da prática social do sujeito que aprende [sic] o objeto na - e pela - sua

\footnotetext{
${ }^{3}$ A Teoria do Reflexo foi exposta por Lênin em Materialismo e empiriocriticismo, de 1909. Para mais detalhes ver Lênin (1982).

${ }^{4}$ Sobre a filosofia subjetivista e o idealismo alemão ver Kant (1973)
} 
atividade. Tanto o sujeito como o objeto mantêm a sua existência objetiva e real, ao mesmo tempo em que atuam um sobre o outro.

Schaff propõe o modelo ativista da relação cognitiva como uma terceira via em relação aos modelos anteriores, baseado em três elementos da filosofia marxiana: ${ }^{5}$

- A tese sobre o indivíduo humano como conjunto das relações sociais;

- A concepção marxista do conhecimento como uma atividade prática, sensível e concreta;

- A concepção do conhecimento verdadeiro como um processo infinito, visando a verdade absoluta através da acumulação das verdades relativas.

Adotamos o modelo ativista do conhecimento proposto por Schaff, por concordar que o conhecimento não é produto ou resultado, mas sim um processo construtivo infinito baseado na interação humana. Esta noção de conhecimento está associada à idéia de que o objetivo da ciência, particularmente das Ciências Humanas e Sociais, não é produzir verdades definitivas, mas sim a busca incessante por aperfeiçoamento das verdades. Ou conforme as palavras de Engels sobre a gnosiologia marxiana citadas por Schaff (op. cit.):

Se a humanidade chegasse alguma vez a operar apenas com verdades eternas...isto queria dizer que tinha chegado ao ponto em que a infinidade do mundo intelectual havia se esgotado. (ENGELS, 1963, apud SCHAFF, 1986, p. 97)

A partir desta concepção do conhecimento, pode-se realizar uma inferência para o conceito de verdade: se o conhecimento é um processo, podemos entender que a verdade também o é (SCHAFF, op. cit.).

Yuexiao (1987) estimou que existem mais de 400 definições para o termo informação, apresentadas por pesquisadores de diferentes campos e culturas. Esta é uma razão pela qual consideramos importante a apresentação do conceito de informação adotado em um trabalho acadêmico na área de Ciência da Informação.

\footnotetext{
${ }^{5}$ Para maiores detalhes ver Marx (1982 [1845]) 
Compreende-se informação como processo essencialmente humano associado à ampliação da consciência acerca da possibilidade de conhecer e agir, isto é, o processo informacional reúne elementos para se transformar o contexto individual ou social a partir do conhecimento e da ação. ${ }^{6}$

Considera-se que este conceito de informação é coerente com o modelo ativista do conhecimento proposto por Schaff. Além disso enfatiza a relação da informação com a ação através do conhecimento, o que parece bastante adequado para o entendimento da história, e em particular para uma reflexão sobre a possibilidade de transformação social através dos processos informacionais que ocorrem no ciberespaço.

De acordo com o conceito de informação proposto por Silva, vale destacar ainda que, no universo digital, conteúdo informacional difere de informação, consistindo em uma representação armazenada (uma dimensão, uma grandeza localizada no ciberespaço), que significa alguma coisa, e que para compreendê-la a representação é preciso referenciar o contexto em que é utilizada (VACARIU et al., 2001). O conteúdo informacional é, portanto, um elemento constituinte dos processos de informação e conhecimento.

\section{As teorias sociais do conhecimento e sua aplicação para as relações para as relações humanas no ciberespaço}

Alguns dos principais psicólogos e educadores do século XX que pesquisaram a relação entre a cognição e o aprendizado, como Vygotsky (1998), Paulo Freire (1982) e Feuerstein (1980), destacaram a importância da interação social no desenvolvimento intelectual humano. ${ }^{7}$

Vygotsky enfatizou o papel da comunidade na construção do conhecimento, através de um processo sócio-histórico. Embora o ser humano possua potenciais inatos de conhecimento e cognição, as funções psicológicas superiores decorrem, em sua maior parte, de um processo de aprendizagem e desenvolvimento social. (FERNANDES, 1998).

\footnotetext{
${ }^{6}$ Cf. Silva (2002).

${ }^{7}$ Sobre Feuerstein, ver também Varela (2003). 
O conceito de funções psicológicas superiores proposto por Vygostky diz respeito a combinações mais complexas de funções mentais, desenvolvidas através da interação social, e que distinguem o comportamento humano do comportamento dos animais. Vygostky ilustra, como exemplo, a introdução na espécie humana de maneiras auxiliares de memorização: contar nos dedos, amarrar barbantes nos dedos para não esquecer de alguma coisa, dentre outros.

Feuerstein reforçou a importância de indivíduos mediadores e de ferramentas adequadas para a ampliação da capacidade de aprendizado:

A aprendizagem humana (...) não se limita a uma pura exposição direta a objetos, acontecimentos, atitudes e situações, mas emerge de uma relação sujeito-mundo que é mediatizada por outro sujeito mais experiente, cujas práticas e crenças culturais são transmitidas às novas gerações, promovendo zonas mais amplas de desenvolvimento cognitivo crítico e criativo. (FEUERSTEIN, 1980, apud VARELA, 2003, p. 18)

Freire, em campanhas de alfabetização, adaptou seus métodos educacionais ao contexto histórico e cultural de seus alunos, possibilitando a combinação de conceitos "espontâneos" (baseados na prática social) com os conceitos introduzidos pelos professores na sala de aula (FREIRE, 1982, apud VYGOTSKY 1998).

$\mathrm{Na}$ época em que estas teorias sociais do conhecimento e do aprendizado foram formuladas, ainda não existiam as redes de computadores e o ciberespaço. Retomando a questão formulada por Calderon e Laserna (op.cit.) sobre a tensão dialética entre a Rede e o Ser, nos pusemos a imaginar sobre como o ciberespaço seria considerado por estes psicólogos e educadores no processo de construção do conhecimento: eles restringiriam o conhecimento à interação humana presencial? Considerariam o ciberespaço como um ambiente de comunicação no qual as relações humanas possibilitam a construção de conhecimento?

\subsection{O ciberespaço como movimento social de interação coletiva}

Para Lévy (1999), o espaço cibernético ou ciberespaço é mais o efeito e resultado de um movimento social, que do desenvolvimento tecnológico. Ou seja, a tecnologia é a 
ferramenta que propicia a transformação, como afirma Castells (op.cit.), mas o movimento social é quem produz e caracteriza o novo espaço resultante.

Lévy aponta a construção cooperativa internacional da internet através de iniciativas locais como o movimento social que inventou o "verdadeiro" uso dos computadores e da rede telefônica, e compara este movimento ao surgimento dos correios: não foi o desenvolvimento dos transportes que fez surgir o correio, mas sim a cultura da correspondência entre os indivíduos. Assim também pode ser vista a relação entre as redes de computadores e o ciberespaço. O autor descreve este movimento social que constitui o ciberespaço como "prática de comunicação interativa, recíproca, comunitária e intercomunitária [...] no qual cada ser humano pode contribuir". (LÉVY, 1999, p.126).

Analisando o conceito do ciberespaço proposto por Lévy, podemos destacar dois aspectos importantes acerca da construção de conhecimento no ciberespaço:

- O primeiro aspecto é o fato do ciberespaço ser o único meio que possibilita a comunicação de muitos para muitos, em uma escala global. Ou seja, diferente de outros meios de comunicação de massa tradicionais, como o rádio e a TV, que alcançam igualmente um grande contingente humano, o ciberespaço possibilita a interação coletiva entre os indivíduos;

- O segundo aspecto a ser destacado, decorrente desta interação coletiva, é o potencial de se tornar uma prática de comunicação ao mesmo tempo universal e não-totalizante. ${ }^{8}$ Lévy entende por totalidade “a conjunção estabilizada do sentido de uma pluralidade (discurso, situação, conjunto de acontecimentos, sistema, etc.)." (LÉVY, 1999, p. 121)

No âmbito cultural, entende-se que os meios de comunicação de massa tradicionais favorecem a construção de sentidos de cunho totalizante, devido a seu fluxo unidirecional de comunicação. Os filósofos da Escola de Frankfurt, em especial Horkheimer e Adorno, denominaram de "indústria cultural" a conversão da cultura em bens de consumo de massa.

\footnotetext{
${ }^{8} \mathrm{O}$ conceito marxiano de totalidade difere deste empregado por Lévy. Na teoria marxiana, a totalidade é a estrutura significativa da realidade, proporcionada por uma visão de conjunto obtida através do processo de síntese (Cf. Konder, 2004).
} 
As formas de representação da indústria cultural anulam os mecanismos da reflexão e crítica para acionarem a percepção e os sentidos. Freitag (1986) entende que este efeito da indústria cultural tem uma função social específica, que é ocupar o espaço de lazer do indivíduo sem lhe dar espaço para refletir sobre sua realidade.

A indústria cultural é, portanto, um exemplo de representação totalizante, por ser imposta com um propósito e ideologia específicos, sem estimular a capacidade crítica. As representações totalizantes, de um modo geral, sobrevivem justamente da ausência de interatividade e de reflexão entre os indivíduos. Remetendo à teoria ativista do conhecimento proposta por Schaff e à gnosiologia marxiana, as representações totalizantes se aproximam das verdades eternas, do esgotamento do processo intelectual humano e da interrupção do processo de informação.

Lévy (2001) destaca que quanto mais o ciberespaço se universaliza, isto é, quanto mais interconectado e interativo, menos totalizável ele se torna, uma vez que cada conexão suplementar e cada indivíduo agregado à rede lhe conferem mais heterogeneidade, mais diversidade de opiniões, e portanto maior possibilidade de construção de conhecimento.

O hipertexto, uma das formas de representação mais difundidas na internet, é um símbolo da interatividade proporcionada pelo ciberespaço. Moraes (2001, p.68) destaca que "nos encadeamentos do hipertexto, cada ator inscreve sua identidade na rede à medida que elabora sua presença no trabalho de seleção e de articulação com as áreas de sentidos."

Este aspecto do hipertexto proporciona uma nova visão à dialética entre a Rede e o Ser. As particularidades de cada indivíduo exercem um papel importante na dinâmica da comunicação através do hipertexto. Baseado em suas identidades, o indivíduo navegador seleciona a sequência de leitura dos links, e participa da construção da mensagem comunicada.

Conforme observado por Silva (2002), a disseminação dos conteúdos hipertextuais através das redes mundiais de comunicação se caracteriza como uma cadeia não-linear e aleatória, na qual o conteúdo buscado por um indivíduo pode corresponder a uma ação decorrente da informação para outro, que publicou o conteúdo na rede para ser acessado por outras pessoas. 
Lévy (1999) reforça que as próprias páginas da Web, além do conteúdo informacional representado, frequentemente oferecem a possibilidade de comunicação direta entre o autor e o navegador, seja através de correio eletrônico, ou através de fóruns de discussão. Se lembrarmos que este processo pode ocorrer em escala global, independente da localização geográfica de seus participantes, podemos constatar o potencial do ciberespaço para a construção de conhecimento a partir das interações sociais que surgem nesta prática de comunicação.

\section{As comunidades virtuais de conhecimento}

No campo sociológico, a discussão sobre comunidades refere-se mais frequentemente a três aspectos: o espaço geográfico, as interações sociais e os laços comuns. A proximidade física tornou-se menos relevante para o estabelecimento de comunidades, de acordo com novos paradigmas das ciências sociais da segunda metade do século XX. As interações sociais entre os atores caracterizam as comunidades, e passaram a desempenhar papel importante na produção de conhecimento. ${ }^{9}$ Esta afirmação nos parece coerente com a tese de Marx (op.cit) contra Feuerbach, citada anteriormente, que afirma que o homem é o conjunto de suas relações sociais.

Lévy define o virtual como "toda entidade 'desterritorializada', capaz de gerar diversas manifestações concretas em diferentes momentos e locais determinados, sem contudo estar ela mesma presa a um lugar ou tempo particular.” (LÉVY, 1999, p. 47)

De acordo com Recuero (2002), Rheingold foi um dos pioneiros na utilização do termo "comunidade virtual" para os grupos humanos que mantêm relações no ciberespaço, definindo o termo da seguinte forma:

As comunidades virtuais são agregados sociais que surgem da Rede [Internet], quando uma quantidade suficiente de gente leva adiante essas discussões públicas durante um tempo suficiente, com suficientes sentimentos humanos, para formar redes de relações pessoais no espaço cibernético. (RHEINGOLD, 1996, apud RECUERO, 2002, p. 6).

${ }^{9}$ Cf. Costa (2000). 
Embora esta definição de comunidade virtual não seja consistente, ela é importante por destacar o conceito de relações pessoais através do ciberespaço. Para Lévy, "uma comunidade virtual é construída sobre as afinidades de interesses, de conhecimentos, sobre projetos mútuos, em um processo de cooperação ou de troca, tudo isso independentemente das proximidades geográficas e das filiações institucionais." (LÉVY, 1999, p. 127).

Propõe-se, portanto, a partir dos conceitos apresentados, a definição de comunidades virtuais de conbecimento (CVC) como os agregados sociais que surgem na rede a partir das interações de indivíduos que, independente de suas localizações geográficas, trocam impressões e saberes sobre determinado tema de interesse de forma constante, possibilitando o conhecimento e a ação em decorrência destas interações.

Um erro a que se incorre no debate sobre as CVC é pensá-las como uma substituição às formas de comunicação tradicionais, como o contato presencial e a mídia impressa. Seria o mesmo que, por ocasião da invenção do telefone, discutir se algum dia toda a comunicação humana ocorreria através de telefonemas. Um meio de comunicação não substitui outro, mas complementa os meios existentes através de um conjunto de características diferenciadas.

Um exemplo ilustrativo do potencial da aplicação de CVC está na integração dos movimentos de cunho social - a chamada cibermilitância. Segundo Moraes (op. cit.), as questões sociais e ambientais relacionadas à globalização adquirem proporções planetárias, e requerem respostas de igual amplitude e velocidade. O ciberespaço se revela um modelo alternativo de expressão, interativo, cooperativo e descentralizado, que dinamiza os esforços de intervenção dos organismos da sociedade civil na cena pública. Moraes enumera, dentre as diversas ferramentas de intervenção disponibilizadas através da internet, as campanhas virtuais, o correio eletrônico, os grupos de discussão, as salas de conversação, os boletins, manifestos on-line, murais, e árvores de links. O autor destaca que a internet permite ampliar a circulação do conteúdo das entidades ligadas ao ativismo social em escala planetária e a custo baixo, algo impensável em qualquer outro veículo, devido às despesas astronômicas. 
Capra (2002) afirma que, graças à internet, as Organizações Não-Governamentais (ONG) têm conseguido se organizar em redes, trocar dados relevantes e mobilizar seus membros com uma rapidez antes inconcebível. $O$ autor destaca que a primeira demonstração do poder de mobilização das ONG pelo ciberespaço se deu por ocasião da preparação das ações conjuntas contra a reunião da Organização Mundial do Comércio (OMC) em Seattle em 1999. Esse movimento, planejado com meses de antecedência por mais de 700 ONG através de comunidades do ciberespaço, levou mais de 50.000 pessoas às ruas de Seattle em um protesto organizado e não-violento, e representou um marco na integração mundial das ONG, a chamada Coalizão de Seattle.

As ações de cibermilitância através do ciberespaço servem como referência do potencial das CVC em termos de agilidade e reciprocidade para a interação coletiva e o intercâmbio de saberes em escala global. Estas comunidades vêm se desenvolvendo desde o surgimento da internet, possibilitando discussões sobre os mais diversos temas de interesse, desde o entretenimento até temas científicos, como tecnologia, medicina e filosofia.

Retornando à questão da aplicação das teorias sociais do conhecimento às CVC, entende-se que, embora apresentem características distintas da interação humana presencial, as CVC também constituem processos de informação que possibilitam a ampliação da consciência humana quanto à sua capacidade de conhecer, visando à ação e transformação da sociedade. E consistem, por este motivo, em uma prática de comunicação de grande relevância para a humanidade, dada a sua possibilidade de interação coletiva e recíproca de forma descentralizada, e em escala global.

Trata-se, todavia, de uma prática de comunicação ainda recente, e que deve ser pesquisada e desenvolvida visando ao seu aperfeiçoamento e à disseminação de seu uso.

\subsection{A legitimidade do conteúdo informacional no ciberespaço: um paralelo com a crise de consciência européia do século XVII}

A legitimidade do conteúdo informacional representado no ciberespaço é uma das discussões recorrentes sobre esse ambiente. Cmo ter certeza de quem é o nosso 
interlocutor, ou o autor de um determinado conteúdo? E como garantir a veracidade do conteúdo que acessamos?

Weitzel (2006) destaca o mito no qual o discurso científico se perde na internet, devido às múltiplas possibilidades de discursos nesse meio de comunicação, e devido também à ausência de políticas de preservação digital, que afetam a legitimidade do conteúdo informacional.

Steiner (1993) resumiu de forma irreverente a questão da legitimidade do conteúdo na internet, através de um cartum publicado no jornal The New Yorker, ainda na época da abertura comercial da rede mundial de computadores. No cartum, dois cachorros estão diante do monitor de um computador; um deles, sentado na cadeira à escrivaninha, com as patas no teclado, comenta para o outro: On the Internet, nobody knows you're a dog. ${ }^{10}$

A desconfiança sobre o conteúdo informacional representado na internet não é exclusividade desse meio de comunicação. Burke (2003) destaca que, nos séculos XVI e XVII, a "explosão da informação" ocasionada pela disseminação da prensa tipográfica causou uma "crise" relacionada à legitimidade do conhecimento. O maior acesso aos livros possibilitou que mais pessoas pudessem perceber as discrepâncias entre as descrições de um mesmo fenômeno ou relatos de um mesmo evento:

Como comentou um inglês em 1569 , 'temos todo dia várias notícias, e às vezes se contradizem, mas todas são apresentadas como verdadeiras'. O surgimento da gazeta de notícias no século XVII tornou a falta de confiabilidade dos relatos dos 'fatos' mais visível para maior número de pessoas do que nunca, pois relatos rivais e discrepantes dos mesmos eventos, por exemplo, batalhas, chegavam ao mesmo tempo às principais cidades, e, assim, podiam ser comparados e contrastados. (BURKE, 2003, p.180).

Burke adaptou o termo crise, utilizado originalmente na medicina para designar o momento crítico de uma doença, com o objetivo de explicar o termo "crise da consciência européia", utilizado em referência ao final do século XVII, como um período relativamente curto de confusão ou turbulência, que leva à transição de uma estrutura intelectual para outra.

10 "Na internet, ninguém sabe que você é um cachorro." 
Essa turbulência observada no momento histórico da transição intelectual motivada pela mídia impressa parece similar ao que ocorre atualmente com o ciberespaço, e em particular em relação ao sentimento de desconfiança quanto ao conteúdo informacional disponível neste ambiente.

Dentre os métodos e práticas que passaram a ser utilizados pelos filósofos do século XVII como tentativa de solução para a crise de consciência identificada à época, dois serão descritos aqui por sua particular aproximação ao tema que investigamos.

O primeiro relaciona-se à veracidade do conhecimento histórico, os filósofos passaram a dar mais ênfase à probabilidade do que à certeza, e a distinguir entre diferentes graus de aceitação para a verdade. Uma questão confirmada por "afirmações concorrentes de fontes insuspeitas" tendia a ser aceita com menor questionamento. (LOCKE, 1796, apud BURKE, 2003, p.185).

A percepção do conhecimento como processo que acumula verdades relativas parece coerente com esta idéia de Locke de "graus de aceitação" para a verdade. O método empregado pelos historiadores do século XVII, de dar mais credibilidade a um conteúdo quanto mais afirmações de fontes distintas ele possua, é semelhante ao que se pratica atualmente no ciberespaço. Quanto mais indivíduos atestam e/ou criticam um conteúdo informacional publicado em uma comunidade, mais provável e mais confiável aquele conteúdo se torna.

O segundo está associado à utilização da nota de pé de página, prática que passou a ser utilizada de forma cotidiana a partir do século XVII:

O termo "nota de pé de página" não deve ser tomado literalmente. O importante era a difusão da prática de dar algum tipo de orientação ao leitor de um texto particular sobre aonde ir para encontrar a evidência ou informações adicionais, fosse essa informação dada no próprio texto, à sua margem, ao pé, ao final ou em apêndices especiais de documentos. (BURKE, 2003, p.185).

A prática de utilização das notas de pé de página pode ser considerada uma antecessora do hipertexto que encontramos no ciberespaço. As referências a outras fontes complementares ao conteúdo informacional representado (os links do hipertexto) dão maior sustentação ao leitor, contribuem para aumentar sua 
confiabilidade, e promovem a interconexão entre os conteúdos informacionais da teia do ciberespaço.

Os pontos abordados nesta seção demonstram que a desconfiança em relação à legitimidade das representações não surge com o advento da internet. Conforme apontado por Burke, este mesmo sentimento pode ser observado em outros momentos históricos de mudança na estrutura intelectual da sociedade, assim como ocorreu no final do século XVII com a difusão da mídia impressa. Os filósofos e historiadores daquela época incorporaram métodos que contribuíram para prover autenticidade aos conteúdos que eram disseminados. Inclusive alguns destes métodos têm relação com as práticas que se observam atualmente no ciberespaço.

Acredita-se, portanto, que a partir do movimento social que constrói e caracteriza o ciberespaço, vêm surgindo mecanismos que possibilitam a ampliação do nível de confiança sobre essa prática de comunicação, e que contribuem para a desmistificação de seu uso para o processo de construção do conhecimento humano.

\section{Considerações finais}

Neste artigo foi proposta uma reflexão acerca do processo de construção de conhecimento no ciberespaço, apresentando alguns conceitos que fundamentam nossa abordagem.

O Informe Mundial da Unesco afirma que a Sociedade do Conhecimento pode ser considerada uma evolução da Sociedade em Rede que propicia uma melhor tomada de consciência dos problemas mundiais. Os prejuízos causados ao meio ambiente, os riscos tecnológicos, as crises econômicas e a pobreza são elementos que se podem tratar melhor mediante a cooperação internacional e a colaboração científica. (UNESCO, op.cit.).

Considera-se que as comunidades virtuais de conhecimento no ciberespaço poderão contribuir de forma significativa como prática de comunicação para esta transição à Sociedade do Conhecimento. A questão é como desenvolver e disseminar o uso destas comunidades para que elas cumpram este papel de forma efetiva. 
No projeto de pesquisa de mestrado que deu origem a este artigo, pretende-se investigar exemplos de comunidades virtuais, identificando as melhores práticas de aplicação da interatividade coletiva possibilitada pelo ciberespaço para a construção de conhecimento.

A continuidade da pesquisa, considerando sua inserção no campo de estudo da Ciência da Informação, enfatizará os desdobramentos sociais do conhecimento e da informação a partir do uso da tecnologia. O presente artigo insere-se como ponto de partida deste trabalho, através da apresentação e argumentação dos conceitos nos quais se fundamentará a análise dos processos informacionais que podem ocorrer nas comunidades virtuais, e a ampliação da consciência humana sobre a possibilidade de transformação da sociedade a partir do conhecimento.

\section{Referências:}

BURKE, Peter. História Social do Conhecimento: de Gutemberg a Diderot. Rio de Janeiro: Jorge Zahar, 2003

CANCLINI, Néstor Garcia. Consumidores e cidadãos: conflitos multiculturais da globalização. Rio de Janeiro: UFRJ, 1995.

CALDERON, Fernando; LASERNA, Roberto. Paradojas de la Modernidad. Sociedad y cambios en Bolivia. La Paz: Fundacion Milenio, 1994. Apud Castells, 1999.

CAPRA, Fritjof. As Conexões Ocultas: Ciência para uma Vida Sustentável. São Paulo: Editora Cultrix, 2002.

COSTA, Sely M.S. Mudança no processo de comunicação científica: o impacto do uso de novas tecnologias. In: MUELLER, Suzana Pinheiro Machado.

Comunicação científica: estudos avançados em ciência da informação.

Brasília: UNB, 2000. p.85-105.

ENGELS, Friedrich. Anti-Duhring. Paris: Editions Sociales, 1963. Apud Schaff, 1986. 
FERNANDES, Jorge. Ciberespaço: Modelos, Tecnologias, Aplicações e Perspectivas: da Vida Artificial à Busca por uma Humanidade Auto-Sustentável. Sociedade Brasileira de Computação, 1998 v. II p. 109-162 Disponível em http://www.cic.unb.br/docentes/jhcf/MyBooks/ciber/ciber.pdf. Acessado em 10/07/2006

FREIRE, Paulo. Pedagogia do Oprimido. Ed. Paz e Terra, 11 ${ }^{\mathrm{a}}$ ed., 1982. Apud Vygotski, 1998.

FEUERSTEIN, Reuven. Instrumental enrichment: an intervention program for cognitive modifiability. Baltimore, MD: University Park, 1980. Apud Varela, 2003.

FREITAG, Barbara. A Teoria Crítica: Ontem e hoje. São Paulo: Brasiliense, 1986.

GASPARI, Elio. O mundo do Krakatoa melhorou. Folha de São Paulo. 29 de dezembro de 2004. Disponível em:

http://www.jornaldaciencia.org.br/Detalhe.jsp?id=24378 Acessado em 10/07/2006

KANT, Immanuel. Crítica da razão pura. Trad. Rohden/Moosburg. Col. Os Pensadores. São Paulo: Ed. Abril, 1973.

KONDER, Leandro. O que é dialética. $28^{a}$ ed. São Paulo: Brasiliense, 2004.

LÊNIN, Vladimir I. Materialismo e empiriocriticismo. Lisboa: Avante!, 1982.

LÉVY, Pierre. Cibercultura. São Paulo: Editora 34, 1999

LÉVY, Pierre. A Conexão Planetária : o mercado, o ciberespaço, a consciência. São Paulo: Editora 34, 2001

LOCKE, John. An Essay Concerning Human Understanding. T. Longman, 1796. Disponível em http://books.google.com Acessado em 10/o7/2006. Apud Burke, 2003.

MARX, Karl. Teses sobre Feuerbach. Tradução de Álvaro Pina. Lisboa, Avante!, 1982. Disponível em http://www.marxists.org/portugues/marx/1845/tesfeuer.htm Acessado em 16/09/2006

MORAES, Denis. O Concreto e o Virtual: Mídia, Cultura e Tecnologia. Rio de Janeiro: DP\&A, 2001.

RECUERO, Raquel da C. Comunidades Virtuais: Uma Abordagem Teórica. Artigo apresentado no V seminário Internacional de Comunicação, GT de Tecnologia das Mídias. (outubro de 2002). Disponível em: http://www.pontomidia.com.br/raquel/ Acessado em 13/10/2005

RHEINGOLD, Howard. La Comunidad Virtual: Una Sociedad sin Fronteras. Gedisa Editorial. Colección Limites de La Ciência. Barcelona, 1996.

SARACEVIC, Tefko. Information Science: origin, evolution and relations. In: VAKKARI, P.; CRONIN, B. (Ed.). Conceptions of Library and Information Science. London: Taylor Graham, p.5-27, 1992.

SCHAFF, Adam. História e Verdade. São Paulo. Martins Fontes, 1986 
SILVA, Rubens R.G. Digitalização de acervos fotográficos públicos e seus reflexos institucionais e sociais: tecnologia e consciência no universo digital. Tese. Ciência da Informação. Orientadora: Lena Vania Ribeiro Pinheiro. Rio de Janeiro, PPGCI; UFRJ/IBICT, 282 p., 2002.

STEINER, Peter. The Internet Dog. The New Yorker. 5 de Julho de 1993. Vol.69 (LXIX) no. 20. Pag. 61. Disponível em http://www.unc.edu/depts/jomc/academics/dri/idog.html Acessado em 10/07/2006

UNESCO, Hacia la Sociedad del Conocimento. Ediciones Unesco, 2005

VACARIU, Gabriel; TERHESIU, Dália; VACARIU, Mihai. Toward a very idea of representation. Synthese, Netherlands, n.129, p.275-295, 2001.

VARELA, Aida. Informação e Autonomia: A mediação segundo Feuerstein. Tese. Ciência da Informação. Orientador: Antônio Lisboa Carvalho de Miranda. Brasília, UNB, 420 p., 2003.

VYGOTSKI, L. A formação social da mente. Organizado por Michel Cole et alii. São Paulo: Martins Fontes, 1998.

WEITZEL, Simone R. Comunicação e Produção Científica. In: Poblacion, D.; Witter, G.; Silva J. F. Comunicação Científica: Contexto, Indicadores, Avaliação. Ed. Angellara. São Paulo, 2006

YUEXIAO, Zhang. Definitions and Sciences of Information. In: Information Processing \& Management Vol 24, No 4. Great Britain: Pergamon Press, pp 479-491, 1988. 